

\title{
A Study on Visual Diversity of Japanese Residential Streetscapes
}

\author{
Garu Muni Wathsala Lakpriya Gunawardena, Kubota Yoichi and Kiyotaka Fukahori \\ Graduate School of Science and Engineering, Saitama University, Saitama-shi 338-8570, Japan
}

\begin{abstract}
This study was conducted to find out the available visual diversity in Japanese residential streetscapes. The visual diversity occurs when the visual elements on streetscapes are different to each other. In this study, a field survey as a subjective method and the entropy as an objective method were used as measures of visual diversity. Data were collected from 80 residential streetscapes from four sites in the Saitama Prefecture, Japan. The sequential perspective views of streetscapes were analyzed for eight visual elements: shape of houses, shape of roofs, shape of windows, positions of the main openings of houses, availability of the ornaments on houses, height, color and the appearance of the boundary walls of premises to calculate the entropy. A field survey with multicultural subjects was used to find out the correlation between entropy and the human perception on the visual diversity. According to the results, the residential streetscapes displayed high diversity variations largely due to the shape of the roofs, shape of the windows and the appearance of the boundary walls of the premises. Moreover, the results concluded that the residential streetscapes at the study area are neither visually diverse nor visually uniform in considering the visual diversity aspect.
\end{abstract}

Key words: Entropy, streetscapes, visual diversity, visual elements.

\section{Introduction}

\subsection{Diversity}

Sustainable landscape planning and the land management aim to make use of the natures goods and services while producing a pleasant place to the landscape users with minimum harm to the synchronization between the new landscape development and the nature. For this task, maintaining a balanced landscape diversity of the new development to match with the nature is essential. In consequence to maintain a balanced diversity in new development activities, there should be a good knowledge about the diversity and the diversity measurements.

Diversity is a composite measure of richness and evenness and can be computed in a variety of forms depending on the relative emphasis placed on these two components [1, 2]. Pyron [3] explained the

Corresponding author: Garu Muni Wathsala Lakpriya Gunawardena, Ph.D. candidate, research fields: landscape planning, use of remote sensing and GIS for landscape planning. E-mail: w.lakpriya@gmail.com. diversity as the degree of uncertainty within a given enclosing space while Kuiper [4] explained the diversity of landscape components as the expression of vertical relationships between the land use and the abiotic features. In consequence, the diversity can be explained in many ways and the measurement of the diversity is important for the identity of that landscape and to maintain an appropriate diversity among landscapes to have a proper balance between nature and the manmade landscapes.

\subsection{Diversity Measurements}

There are hordes of diversity indices to measure different kinds of diversities. A diversity index is a quantitative measure that reflects how many different types (such as species) there are in a dataset, and simultaneously, takes into account how evenly the basic entities (such as individuals) are distributed among those types. The value of a diversity index increases both when the number of types increases and when the evenness increases. For a given number of types, the value of a diversity index is maximized 
when all types are equally abundant [5]. Landscape diversity indices continue to be employed by landscape ecologists to describe the composition of a landscape using a single number [6-9]. The positive relationships between indices of the species and the landscape diversity have been noted by many researchers as in Refs. [10-12]. Another diversity measuring technique is the use of fractals. Fractals can be used to describe the spatial patterns in the variety of landscape level applications [7, 13, 14]. The development of biodiversity in natural vegetations was measured using on site level (alpha diversity) and on landscape level (gamma diversity) methods as in Ref. [15]. Pragasan and Parthasarathy [16] used Shannon, Simpson, Fisher's alpha indices, Jaccard and Sorensen indices to measure the landscape level tree diversity in tropical forests. Remotely sensed data and GIS (geographic information system) were also used to measure the diversity in landscapes [17].

Every single one of these diversity assessments carried out numerical assessments of plant types or landscape types. They presented the physical conditions or the real field conditions of the landscape. Nonetheless, there is a difference between physical diversity and the visual diversity. Hence for visual diversity assessment, these methods cannot be applied unswervingly and they necessitate some modifications.

\subsection{Visual Diversity}

The visual diversity is the degree of diversity sense by the landscape users and the visitors to the landscape. The visual diversity is a commonly regulated design principle in promoting visual diversity, avoiding monotony, avoiding chaos, or a combination of all three as explained in Refs. [18, 19]. The physical condition of the landscape is not always visible to the viewers. They want to see the relationship between the beauty of the landscape and its richness in terms of bio-ecological factors. It furnishes a visual quality to the landscape. If there is no diversity, the landscape is completely identical. An identical space is tedious to the landscape users and to the viewers. If the landscape is completely diverse in nature, it moreover makes a hectic view to the users. Consequently, there should be a good interaction between diversity and the similarity of landscape to make it a pleasurable place to the users and to the visitors.

In this regard, measuring diversity unit by unit is not important. The main aim is to measure the visual diversity of the landscape features that are visually important for the landscape viewers. The visual diversity is a subjective phenomenon. Sensation of the visual diversity changes from person to person. For one person, a specific landscape is sensed as a highly diverse environment while another may explain it as a good combination of the diversity and the similarity. Hence the definition and the measurement of the visual diversity ought to be carried out with a good concern.

\subsection{Visual Diversity Measurements}

Ref. [20] conducted in the Po Valley region in Italy found the correlation between the beauty of a landscape and its richness in bio-ecological terms. For example, the author found out the elements which visually characterize the landscape, amongst which are hedges, springs, rows of poplars and willows, not only leftovers from the traditional rural landscape giving beauty to the surrounding, but also provide important habitats which can contribute to the heterogeneity and therefore the ecological quality of the landscape. Stamps [21] introduced the concept of statistical entropy as a measure of visual diversity. The paper explained the correlation between the visual diversity and the entropy. Additionally, the author researched on the relationship between the pleasure of the viewers of the landscape and the entropy. Yet for this experiment, he could not obtain a promising relationship. Tucker et al. [22] utilized space syntax method to analyze the visual diversity on the 
streetscapes. By considering the open spaces generated by the existence of an interdependent built boundary extending in scale from the individual house through to the streets that form cities, space syntax attempts to explain human behavior as it occurs in those spaces. Describing the visual character of a streetscape through the analysis of its spatial configuration might then provides an objective measure within a planning field that is dominated by qualitative methods.

However, there was very little past research on the visual diversity of the landscapes. Most of the researchers are interested in finding the physical diversity, not the visual diversity.

\subsection{Overview of the Study}

Visual diversity is a commonly regulated design principle as explained in Refs. [18, 19]. Regen [23] said, "There are several variations of architectural design regulations. Some ordinances contain anti-similarity provisions permitting an architectural board to disapprove a permit for excessive similarity to any other standing or approved structure within a specified distance. These provisions are intended to avoid block after block of homogeneous housing. In contrast, other communities have established regulations prohibiting excessive differences between structures. These provisions seek to encourage some amount of homogeneity. Another type of ordinance prohibits building of structures that are 'inappropriate' in design. Finally, some communities enact statutes which, oddly enough, simultaneously prohibit excessive similarity, dissimilarity, and inappropriateness to the area". Hence, different communities prefer dissimilar extents of visual diversity.

In this study, the Japanese residential streetscapes were studied to find out the level of visual diversity existing on the Japanese residential streetscapes. It will be helpful to find out the level of visual diversity preferred for their living spaces by the native Japanese people. For this attempt, a subjective field survey with
20 multicultural subjects and an objective method (the entropy) were applied. As Stamps [21] put, "advances in visual diversity and entropy" introduced the applicability of entropy for visual diversity measurement. This research followed some of Stamps's findings. However, it mainly focused on finding out the viewer's pleasure and the visual diversity of landscapes. In this research, the main objective is to find out the available visual diversity in the Japanese residential streetscapes using subjective and objective analysis methods.

\subsection{Entropy}

The diversity can be measured using different types of indices. One of such indices is the Shannon's diversity index where it is also known as the Shannon Weaver index and the Shannon entropy. The measure was originally proposed by Claude Shannon to quantify the entropy (uncertainty or information content) in strings of text. The idea is that the more different letters there are and the more equal their proportional abundances in the string of interest, the more difficult it is to correctly predict which letter will be the next one in the string [5]. The Shannon entropy $\left(H^{\prime}\right)$ quantifies the uncertainty (entropy or degree of surprise) associated with this prediction. It is most often calculated as follows:

$$
H^{\prime}=-\sum P_{i} \cdot \ln P_{i}
$$

where, $P_{i}$ is often the probability of individuals belonging to the $i$ th landscape type in the landscape of interest. Subsequently, the Shannon entropy quantifies the uncertainty in predicting the identity of an individual landscape that is taken at random from the whole landscape.

In this research, $P_{i}$ is considered as the probability of individuals belonging to the $i$ th visual element of the streetscape, e.g., $P_{i}$ - the probability of rectangular windows.

Assumptions of the research are as follows:

(1) If the entropy value of a visual element is high, the contribution of that visual element to the 
streetscape visual diversity becomes high;

(2) If a streetscape has a high overall entropy value, the visual diversity of that streetscape is high.

Fig. 1 shows the assumptions in a diagram for further clarification.

\section{Method}

\subsection{Study Area}

The research was conducted in four different sites of the Saitama Prefecture, Japan. Fig. 2 displayed the selected sites.

The residential streetscapes were selected from Urawa, Chuo, Saitama and Omiya wards. From each ward, 20 residential streetscapes were selected. The length of the selected streetscapes was around $200 \mathrm{~m}$ from the beginning to the end. The streetscapes were comprised of largely two stories single family residential units. Occasionally, one story and three or

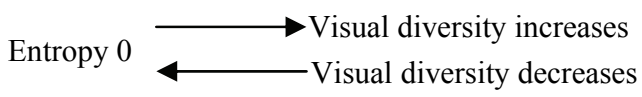

Fig. 1 Assumptions in a diagram.

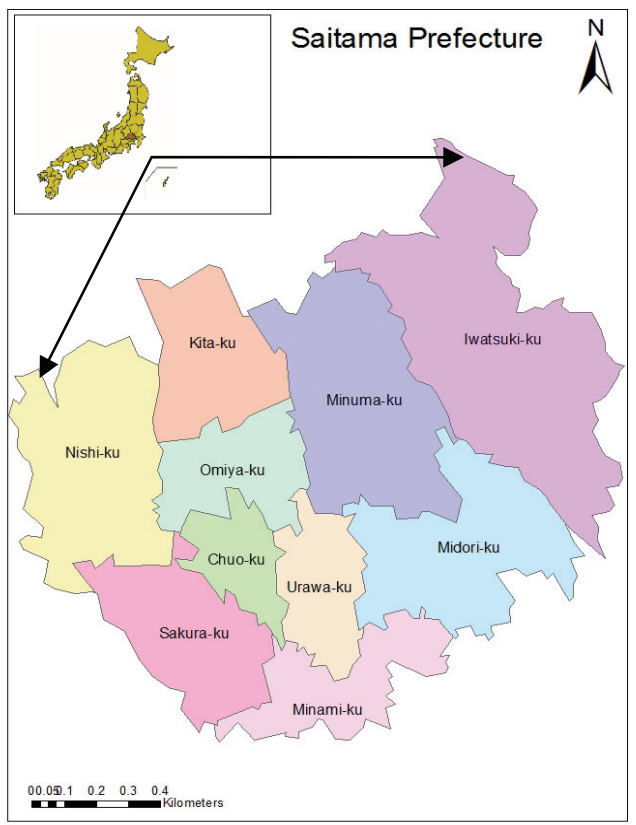

Fig. 2 The study area. more stories single family buildings were positioned in the study area. Auxiliary, in some streetscapes, housing complexes could be seen. The houses were built very near to the street line with a very small open space in front of the houses. Most of the time, this small open space is used as a parking place for the vehicles. Along the streetscape parking lots, home gardens, small retail shops and rarely religious places could be observed. Some of the photographs of the study area are given in Figs. 3 and 4.

The method included two sections: analysis of the perspective views of the streetscapes and the subjective analysis of the streetscapes.

\subsection{Perspective Views Analysis of the Streetscapes}

Along the selected residential streetscapes, perspective photographs were taken from five viewpoints to cover either side of the streetscapes. Perspective views were analyzed to symbolize the view

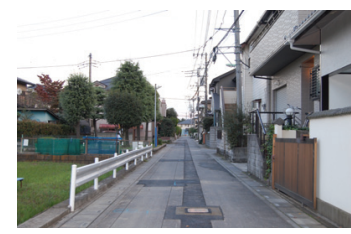

(a)

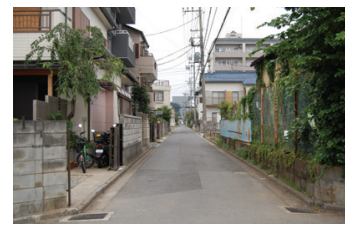

(c)

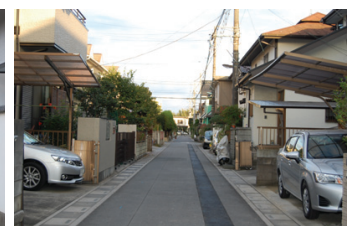

(b)



(d)
Fig. 3 Perspective views of the study area with: (a) housing gardens; (b) parking lots; (c) housing complexes; (d) retail shops.

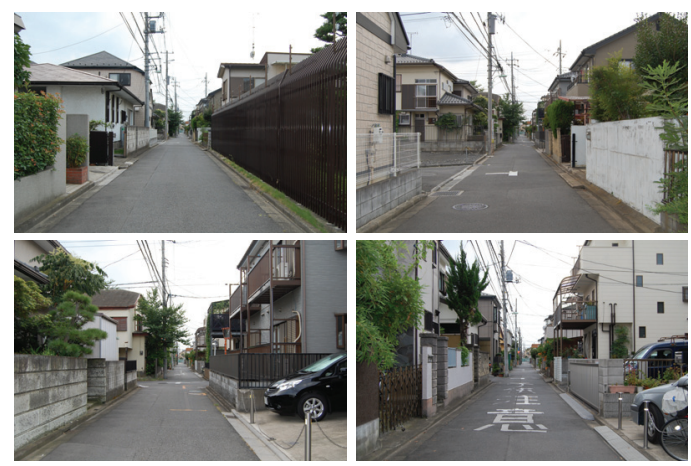

Fig. 4 Serial perspective views along one selected streetscape. 
of pedestrians travelling along the street. Fig. 3 displays sequential perspective views taken at the selected viewpoints along a selected residential streetscape.

Eight visual elements were analyzed in the streetscape views. Analyzed elements and their levels are given in the Table 1.

The visual elements of the residential units at the considered 80 streetscape views were categorized into the selected elements groups above and the levels with the help of perspective views. The counted numbers under each element and the levels were utilized for the entropy calculation in Excel. The entropy values were obtained separately for each element. The total entropy for a streetscape was obtained by adding the entropy values of eight visual elements together.

\subsection{Subjective Analysis of the Streetscape Views}

The obtained perspective views along 80 residential streetscapes were displayed to 20 multicultural subjects. The subjects were selected from the Saitama University representing Japan, Sri Lanka, India, Pakistan, Bangladesh and China. Table 2 displays the number of subjects selected from each country. Native Japanese students represented half of the subjects. It was purposely arranged to find out whether there is any difference between the perception of the visual diversity by native Japanese people on their own streetscapes and the foreigners on the streetscapes which may be different in visual diversity from their countries.

The subjects were asked to mark the visual diversity level of each streetscape in a five-point scale after carefully observing five perspective views obtained from each streetscape. The five-point scale had five levels of visual diversity Fig. 5 shows the five point scale:

(1) Highly diverse: the residential units are different to each other significantly;

(2) Diverse: the residential units show some differences in their visual characteristics;

(3) Neither diverse nor uniform: the residential units at the streetscape do not show a significant variability in both ends;

(4) Uniform: the residential units are by and large show similar characteristics;

(5) Highly uniform: the residential units and their surroundings are similar to each other. The variability along the streetscape is at a minimum level.

Based on the subjects' view and their individual preferences, the 80 residential streetscapes were categorized into one of the levels of the five-point scale.

Subsequently, the correlation between the calculated entropy and the field survey results was obtained.

\section{Results and Discussions}

\subsection{Results of the Entropy}

The entropy of the streetscapes ranged between 1 and 12 (Fig. 6) displays the graph showing the number of streetscapes under different entropy values. For displaying purpose, the entropy values were grouped into six categories.

There were 29 streetscapes with the entropy in between 6 and 8 while 16 streetscapes had entropy in between 4 and 6 . Entropy of 11 streetscapes ranged

Table 1 Visual elements and their levels.

\begin{tabular}{llll}
\hline Visual element & Level of the visual element & Visual element & Level of the visual element \\
\hline Shape of the roofs & $\begin{array}{l}\text { Flat, mono pitched, gable, hidden } \\
\text { roof, hip }\end{array}$ & Color of houses & White, cream, light brown, light pink, grey \\
Shape of houses & $\begin{array}{l}\text { Square, rectangle, rectangle with } \\
\text { small protrusions, L shape }\end{array}$ & Boundary wall of premises & $\begin{array}{l}\text { Vegetative fence, brick wall, mesh, brick } \\
\text { wall with a mesh, poles }\end{array}$ \\
Shape of windows & $\begin{array}{l}\text { Square, rectangle, full round, quarter } \\
\text { round with extended leg, trapezoid } \\
\text { Height of houses }\end{array}$ & $\begin{array}{l}\text { Single story, two stories, three stories, Availability of ornaments } \\
\text { four or more stories }\end{array}$ & $\begin{array}{l}\text { Bulbs, decorative openings, ornaments on } \\
\text { on houses }\end{array}$ \\
\hline
\end{tabular}


Table 2 The selected subjects from each country.

\begin{tabular}{ll}
\hline Country & Number of students \\
\hline Japan & 10 \\
Sri Lanka & 4 \\
China & 2 \\
India & 2 \\
Bangladesh & 1 \\
Pakistan & 1 \\
\hline
\end{tabular}

$\begin{array}{ccccc}1 & 2 & 3 & 4 & 5 \\ \begin{array}{l}\text { Highly } \\ \text { diverse }\end{array} & \text { Diverse } & \begin{array}{c}\text { Neither uniform } \\ \text { nor uniform }\end{array} & \text { Uniform } & \begin{array}{c}\text { Highly } \\ \text { uniform }\end{array}\end{array}$

Fig. 5 Five-point scale.

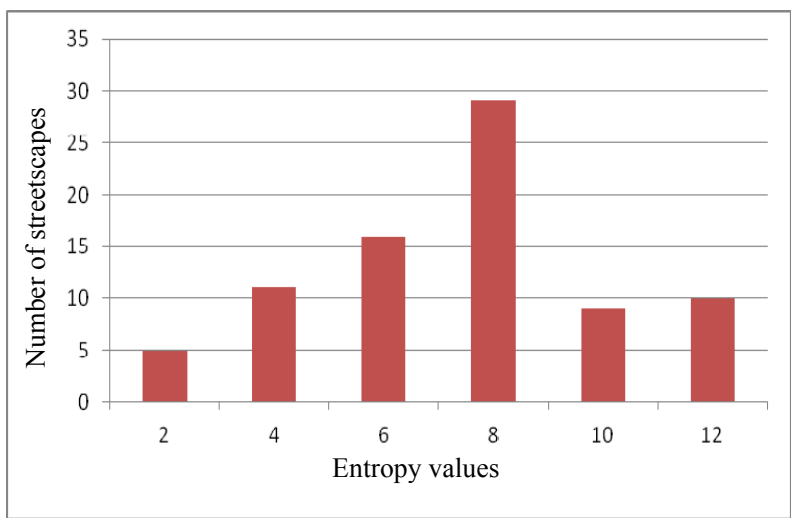

Fig. 6 Number of streetscapes under each entropy category.



Fig. 7 Entropy ranges for eight visual elements.

between 2 and 4 whereas 10 streetscapes acquired entropy in between 10 and 12. Five streetscapes obtained entropy below 2 whilst 9 streetscapes showed entropy in between 8 and 10. In consequence, the entropy of the majority of streetscapes ranged between 4 and 8 .

The next step was to compare the individual entropy of eight visual elements. Fig. 7 displays the entropy ranges of the individual visual elements.

In accordance with the results, the visual elements "shape of the roofs" and the "appearance of the boundary walls of the premises" obtained high entropy. It portrays that these two visual elements principally affect the diversity of the residential units in the selected study area. In addition, "the shape of the windows" has a considerable effect on the overall entropy. Accordingly, out of the considered eight visual elements, the boundary walls of the premises, the shape of roofs and the shape of windows play major roles in the visual diversity of the streetscapes. In almost all streetscapes, the boundary walls of the premises were different from each other: some sites had brick walls while some had vegetative fences. Some premises had just a colored mesh as a wall while some properties had both brick wall and a mesh together. Therefore, it plays a major role in giving visual diversity to the streetscape. Similar qualities could be seen in the shape of the roofs and the shape of the windows. Most of the residential units in the study area were two stories buildings, hence the effect of "building height" had not shown a significant diversity, and additionally, most of the houses were painted in light brown color giving a least diversity in color. Shape of residential units were largely rectangular or rectangular with small protrusions. Consequently, the "shape of the houses" moreover contributed less for the diversity in the streetscapes.

\subsection{Results of the Survey}

Perspective views of the 80 residential streetscapes were displayed to 20 multicultural subjects and they were asked to rank the streetscapes based on the given five-point scale. Afterward, the ranks were counted for each streetscape and the percentage of marking each streetscape under each rank in the five-point scale was calculated. If the percentage was over $50 \%$ under a specific rank, subsequently, that streetscape was grouped under the specified category. Table 3 shows the number of streetscapes under each category 
in the five-point scale.

For the survey, two main groups were used: Japanese and the non Japanese subjects. However, the ranking of the streetscapes by the two groups displayed no significant variation. Hence, both Japanese and non Japanese residents had same trend of perception on the Japanese residential streetscapes.

Survey results illustrated that there were eight streetscapes with a high visual diversity. Similar output was obtained through the entropy resulting 10 streetscapes with entropy higher than 10. These residential streetscapes comprised of housing complexes, some retail shops and some other small scale commercial activities giving dissimilar building architecture to the streetscape. As a result, the visual diversity of these streetscapes increased. Supplementarily, more than $50 \%$ of subjects ranked three streetscapes as highly uniform while entropy displayed five streetscapes with entropy values less than 2.

To have a better comparison between subjective analysis and the entropy, the five-point scale was broadly categorized into three groups: diverse, uniform and neither diverse nor uniform. Similarly, the entropy values were categorized into three groups: the entropy less than 4, entropy in between 4 and 8 and the entropy larger than 8 . Table 4 displays the comparison between entropy groups and the subjective analysis groups.

Both methods proved that the visual diversity of the Japanese residential streetscapes was near to the ground. The selected streetscapes displayed basically neither diverse nor uniform or the uniform characteristics. As a consequence, it can be concluded that the Japanese residential units show similar visual characteristics to each other and the Japanese people prefer more uniformity in the physical structures in their living spaces than a high diversity. Japanese people are nature lovers, hence, the Japanese residential streetscapes were planned to match with the nature with a minimum harm to the harmony between the human developments and the nature. It implies further by the color arrangement of the houses with light brown or dull colors which are the colors of the soil.

Fig. 8 shows two views of highly diverse and highly uniform streetscapes.

The next objective of the research was to find out the correlation between the entropy and the survey results.

Table 3 Ranking of streetscapes.

\begin{tabular}{lll}
\hline $\begin{array}{l}\text { Five point scale } \\
\text { category }\end{array}$ & $\begin{array}{l}\text { No. of streetscapes } \\
\text { under each category }\end{array}$ & Percentage (\%) \\
\hline Highly diverse & 8 & 10 \\
$\begin{array}{l}\text { Diverse } \\
\text { Neither diverse nor }\end{array}$ & 13 & 16.25 \\
uniform & 32 & 40 \\
Uniform & 24 & 30 \\
Highly uniform & 3 & 3.75 \\
\hline
\end{tabular}

Table 4 Major groups of entropy and the survey results.

\begin{tabular}{llll}
\hline Entropy group & $\begin{array}{l}\text { No. of } \\
\text { streetscapes }\end{array}$ & Survey groups & $\begin{array}{l}\text { No. of } \\
\text { streetscapes }\end{array}$ \\
\hline $\begin{array}{l}\text { Entropy less } \\
\text { than } 4\end{array}$ & 16 & Uniform & 27 \\
$\begin{array}{l}\text { Entropy in } \\
\text { between 4 and } 8\end{array}$ & 45 & $\begin{array}{l}\text { Neither diverse } \\
\text { nor uniform }\end{array}$ & 32 \\
$\begin{array}{l}\text { Entropy higher } \\
\text { than } 8\end{array}$ & 19 & Diverse & 21 \\
\hline
\end{tabular}

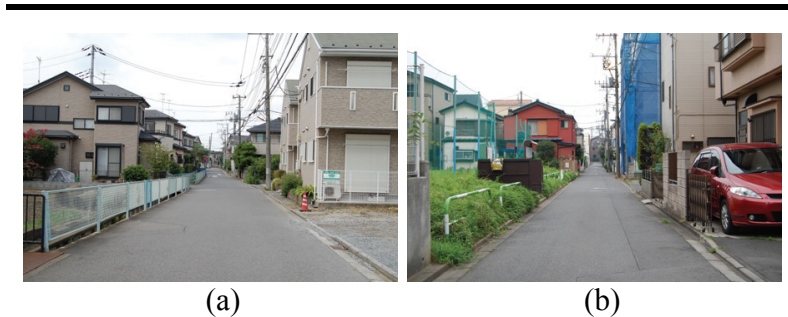

Fig. 8 Perspective views of: (a) highly uniform; and (b) highly diverse residential streetscapes.

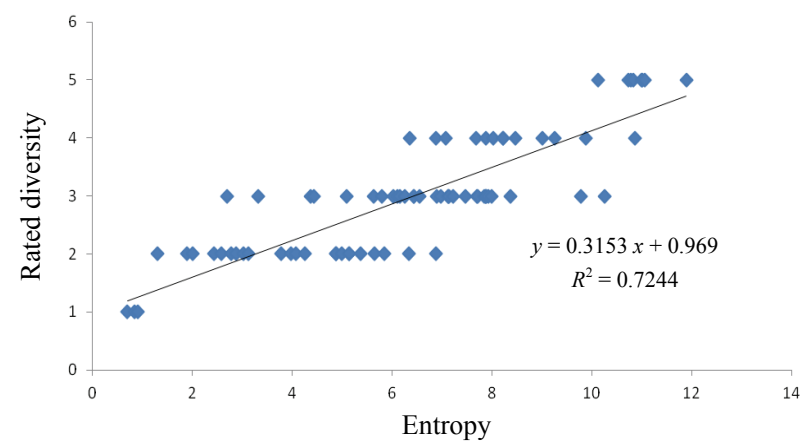

Fig. 9 The correlation between the entropy and the rated visual diversity. 
Fig. 9 displays the correlation between the entropy and the streetscape survey results.

The correlation between the subjects' impression on the visual diversity and the entropy was 0.72 . Consequently, there is a significant correlation between the entropy of the streetscape visual diversity and the human perception on the visual diversity. It implies that the use of entropy for the visual diversity assessment on the residential streetscapes is a prolific effort.

\section{Conclusions}

This study was undertaken to find out the applicability of Shannon's entropy to measure the visual diversity of Japanese residential streetscapes.

The objective analysis of the visual diversity on residential streetscapes using Shannon's entropy equation is a promising effort. The entropy ranged between 1 and 12. Consequently, the entropy equation could be successfully used for the visual diversity measurement on the residential streetscapes.

The perception on the residential streetscapes by Japanese and non Japanese subjects showed no significant difference.

Based on the results, the studied Japanese residential streetscapes acquire high visual diversity fundamentally due to the dissimilar roof styles, the shapes of the windows and the variations in the boundary walls or fences of the premises.

A considerable number of residential streetscapes obtained entropy between 4 and 8. Most of these streetscapes were categorized under "neither diverse nor uniform" category on five-point scale. Accordingly, most of the Japanese residential streetscapes are evidence for no momentous diversity or uniformity. It implies that the Japanese people prefer more calm and unexciting environment for their living space the same as the nature.

Results of the Shannon's entropy calculation and the field survey exhibited a 0.72 correlation proving the employ of entropy calculation for the visual diversity is plausible. Therefore, not only subjective analysis methods, but also objective analysis methods like Shannon's entropy could be applied for the visual diversity assessments.

Future researches can be focused on the use of Shannon's entropy values for proper landscape planning in Japan.

\section{References}

[1] Shannon, C. E., and Weaver, W. 1949. The Mathematical Theory of Communication. Urbana: University of Illions Press.

[2] Simpson, E. H. 1949. "Measurement of Diversity." Nature 163: 688

[3] Pyron, B. 1972. "Form and Diversity in Human Habitats, Judgmental and Attitude Responses." Environment and Behavior 4 (1): 87-120.

[4] Kuiper, J. 1998. "Landscape Quality Based upon Diversity, Coherence and Continuity, Landscape Planning at Different Planning Levels in the River Area of The Netherlands." Landscape and Urban Planning 43 (1-3): 91-104.

[5] Hill, M. O. 1973. "Diversity and Evenness: A Unifying Notation and Its Consequences." Ecology 54: 427-32.

[6] Rey-Benayas, J. M., and Pope, K. O. 1995. "Landscape Ecology and Diversity Patterns in the Seasonal Tropics from Landsat TM Imagery." Ecological Applications 5: 386-94.

[7] Riitters, K. H., O' Neill, R. V., Hunsaker, C. T., Wickham, J. D., Yankee, D. H., Timmins, S. P., Jones, K. B., and Jackson, B. L. 1995. "A Factor Analysis of Landscape Pattern and Structure Metrics." Landscape Ecology 10: 23-39.

[8] Turner, M. G. 1990. "Spatial and Temporal Analysis of Landscape Patterns." Landscape Ecology 4: 21-30.

[9] Ulrich, R. S. 1974. "Scenery and the Shopping Trip: The Roadside Environment As a Factor in Route Choice." In The Experience of Nature: A Psychological Perspective, edited by Kaplan, R., and Kaplan, S. Cambridge: Cambridge University Press, 280-3.

[10] Noderhaug, A., Ihse, M., and Pedersen, O. 2000. "Biotope Patterns and Abundance of Meadow Plant Species in a Norwegian Rural Landscape." Landscape Ecology 15: 201-18.

[11] Pino, J., Roda, F., Ribas, J., and Pons, X. 2000. "Landscape Structure and Bird Species Richness Implications for Conservation in Rural Areas between Natural Parks." Landscape and Urban Planning 49: $35-48$.

[12] Whittaker, R. H. 1972. "Evolution and Measurement of 
Species Diversity.” Taxon 21: 213-51.

[13] Burrough, P. A. 1986. Principles of Geographic Information Systems for Earth Resources Assessment. Oxford: Clarendon Press.

[14] De Cola, L. 1989. "Fractal Analysis of a Classified Landsat Scene." Photogrammetric Engineering and Remote Sensing 55 (5): 601-10.

[15] Whittaker, R. H. 1965. "Dominance and Diversity in Land Plant Communities." Science 147: 250-60.

[16] Pragasan, L. A., and Parthasarathy, N. 2010. "Landscape Level Tree Diversity Assessment in Tropical Forests of Southern Eastern Ghats, India." Flora 205: 728-37.

[17] Lam, N. S. 1990. "Description and Measurement of Landsat TM Images Using Fractals." Photogrammetric Engineering \& Remote Sensing 56 (2): 187-95.

[18] Duerksen, C. J., and Goebel, R. M. 1999. Aesthetics,
Community Character, and the Law. Chicago: American Planning Association.

[19] Lightner, B. C. 1993. Survey of Design Review Practices, Planning Advisory Service Memo. Chicago: American Planning Association.

[20] Nassauer, J. I. 1988. "The Aesthetics of Horticulture, Neatness As a Form of Care." Hortscience (23): 973-7.

[21] Stamps, A. E. 2003. "Advances in Visual Diversity and Entropy." Environment and Planning B: Planning and Design 30 (3): 449-63.

[22] Tucker, C., Ostwald, M., Chalup, S., and Marshall, J. 2005. "A Method for the Visual Analysis of the Streetscape." Presented at the 5th Space Syntax International Symposium, Delft.

[23] Regen, K. 1990. "Aesthetic Zoning." Fordham Law Review 58: 1013-31. 